\title{
Effects on Bacterial Translocation of High-Fat Enteral Nutrition in Bile Duct Ligated Rats
}

\author{
Tufan Elipek ${ }^{1}$ Nihat Zafer Utkan² \\ 'Department of General Surgery, Edirne State Hospital, Edirne, Turkey \\ ${ }^{2}$ Department of General Surgery, Faculty of Medicine, Kocaeli University, Kocaeli, Turkey
}

\begin{abstract}
Objective: Bacterial Translocation (BT) from the gastrointestinal system is at the center of current sepsis theories. In patients with obstructive jaundice, the absence of intraluminal bile flow causes some alterations and mucosal damage in the gut. In the present study, it was aimed to investigate the effects on BT of high-fat enteral nutrition in bile duct ligated rats.

Material and Methods: In this study, a total of 28 healthy Spraque-Dawley rats, weighing 230-300 gr, were grouped into four as sham group, control group, high-fat enteral nutrition group and low-fat enteral nutrition group. The rats in all the groups were sacrificed on the seventh postoperative day The values of aspartate aminotransferase (AST), alanine aminotransferase (ALT), alkaline phosphatase (ALP), gamma-glutamyl transferase (GGT), total and direct bilirubin were measured for biochemical evaluation. Also, samples were taken from the blood, lung, liver, spleen and mesenteric lymph nodes for microbiological evaluation. The results were calculated as CFU/gr and evaluated statistically.
\end{abstract}

Results: In all bile duct ligated rats, all findings of obstructive jaundice were observed clinically (in postoperatively third day) and in the laboratory. It was determined that the lymphatic system is an essential pathway for BT, as reported by similar studies. However, it was observed in this study that the high-fat enteral nutrition may be not severely effective in reducing BT in bile duct ligated rats. The results were supported by statistical analyses.

Conclusion: It was observed that high-fat enteral nutrition has no meaningful effects on reducing BT in bile duct ligated rats.

Key Words: Obstructive jaundice, high-fat enteral nutrition, bacterial translocation

Received: 18.10.2011 Accepted: 01.02.2012

\section{Introduction}

In the physiopathology of obstructive jaundice, the role of endotoxemia demands attention and it is observed that both portal and systemic endotoxins increase in bile duct obstruction (1-6). It is believed that an endotoxin in the portal venous blood passes from the lumen of the gastrointestinal tract by translocation (3-6).

The pathogenesis of bacterial translocation (BT) is not adequately known. However, homeostasis defects among defence mechanisms such as intestinal microflora and mucosal barrier, gastric acidity and gastrointestinal motility may cause BT. When the gastrointestinal barrier has been damaged functionally or physically, some bacteria may be potential pathogens or may be sources of sepsis (7). It is supposed that, in mechanical biliary obstruction, the absence of biliary salts in the gut indirectly increases endotoxin translocation into portal vein blood because the biliary salts hold and inactivate endotoxin (8).

Enteral nutrition prevents mucosal atrophy in the gastrointestinal system and provides completeness of the immune system via the protective normal gut flora (9). High-fat enteral nutrition protects the gut barrier function and reduces en- dotoxemia $(10,11)$. The fat in the diet strongly increases the secretion of biliary salts, which is a potential inhibitor of endotoxin. Healthy secretion of bile is essential for formation of chylomicrons after high-fat enteral nutrition. These lipoproteins, which are rich in triacylglycerol, effectively neutralise the endotoxin and protect the organisms against to mortality caused by endotoxin (12).

The most important target of treatment in bile duct ligation is endotoxin and the inflammatory reply depending on endotoxin. Despite many different experimental studies, no clinical treatment for reducing the high complication rates of the patients with obstructive jaundice after major surgical operation has been reported yet $(13,14)$.

Up to now, some studies which investigate the BT in obstructive jaundice models have been carried out (15-22). In some of them, different materials were given to the models in whom bile duct was ligated to observe their effects on BT (16-22). Erbil et al. (16) have studied the effects of deoxycholate, lactulose and glutamine on BT included by obstructive jaundice. Aldemir et al. (17) have searched the effects of ursodeoxycholic acid, glutamine and polyclonal immunoglobulin on BT in bile duct ligated rats. Luyer et al. (18) have investigated the levels of plasma endotoxin and TNF- $\alpha$ on the models which have bile duct ligation and fed by high-fat nutrition 
during seven days after a hemorrhagic shock procedure. Geyik et al. (21) have studied the effects of an yeast on BT in the models with obstructive jaundice. Gencay et al. (22) have reported the effect of honey on BT in obstructive jaundice. The effects of ciprofloxacin and ursodeoxycholic acid on BT in obstructive jaundice were investigated by Kaya et al. (20). The effects of glutamine and curcumin on BT in the rat models with obstructive jaundice were researched by Karatepe et al. (19).

In this study, the effects of high-fat enteral nutrition on the barrier of gut mucosa were investigated using the bile duct ligated rat models. For this aim, BT in the samples from blood and some tissues Isuch as lung, liver, spleen, mesenteric lymph nodes in the rats which have obstructive jaundice was investigated. Thus, our findings on the effects of high-fat enteral nutrition on BT in obstructive jaundice were discussed with the literature.

\section{Material and Methods}

The present study was performed on the rats from the Unit of Experimental Medicine Researches and Application of Kocaeli University and approved by the Ethical Committee.

A total of 28 healthy Sprague-Dawley rats (without separating sex), weighing $230-300 \mathrm{gr}$, were used in the study. The rats were sorted into four different groups. Every group had 7 rats which has been held in plastic cages in stable environmental conditions. Experimental groups consisted of:

Group A: Sham group; bile duct dissection was done by laparotomy. They were then fed by standard rodent chow during seven days and had free access to water. The experimental processes were used after sacrificing.

Group B: Control group; bile duct ligation was done by laparotomy. They were then fed by standard rodent chow during seven days and had free access to water. The experimental processes were used after sacrificing.

Group C: High-fat enteral nutrition group; bile duct ligation was done by laparotomy. They were then fed by high-fat nutrition during seven days and had free access to water. The experimental processes were used after sacrificing.

Group D: Low-fat enteral nutrition group; bile duct ligation was done by laparotomy. They were then fed by low-fat nutrition during seven days and had free access to water. The experimental processes were used after sacrificing.

\section{Surgical procedures}

The rats were operated with inhalation anaesthesia by ether. He midline of the rats was cleaned for operation using povidon-iodine (Betadin ${ }^{\circledR}$ ) as sterilizer. About $4 \mathrm{~cm}$ midline incision was explored from the xiphoid with passing skin, under skin and fascia. In the Sham Group, only the common bile duct was dissected after laparotomy. In the other groups, the common bile duct was freed after dissection. It was cut after twice binding with silk 4/0. Abdominal strata were closed as continued sutures with 4/0 polypropylene after providing liquid resuscitation by using $5 \mathrm{cc}$ of $0.9 \% \mathrm{NaCl}$ into the abdominal cavity. In the postoperative period, while the rats in the first and second groups were fed on standard rodent chow, the rats in the third group were fed on high-fat nutrition (Glucerna ${ }^{\circledR}$ ) and the rats in the fourth group were fed on low-fat nutrition (Biosorb fibre ${ }^{\circledR}$ ) during seven days.

\section{Biochemical analyses}

Before sacrificing, about 2 cc blood were taken intracardiacally from the subxiphoid area. The blood samples were centrifuged and then $1 \mathrm{cc}$ serum was separated. The values of total bilirubin, direct bilirubin, aspartate aminotransferase (AST), alanine aminotransferase (ALT), alkaline phosphatase (ALP), and gamma-glutamyl transferase (GGT) were measured using Abbot Aeroset.

In all operated bile duct ligated rats, all findings of obstructive jaundice were observed clinically (in third day after operation) and in the laboratory.

\section{Microbiological analyses}

At the end of the feeding days, all rats in all groups were sacrificed by cervical dislocation and then thoraco-laparotomy was done. The blood samples taken from the right atrium of the rats were placed in sterile tubes including $1 \mathrm{cc}$ liquid culture. To investigate BT, tissue samples from the lung, liver, spleen, mesenteric lymph nodes were placed in sterile tubes including $1 \mathrm{cc} 0.9 \% \mathrm{NaCl}$ and weighed. The tissue samples were put into sterile plastic bags and homogenised. These homogenised sterile blood and tissue samples were planted into Petri dish as zigzags by using line sowing methods (shallow planting) under Bunsen burner flame conditions by the sterile loop. The blood samples and homogenised tissue samples were planted in EMB nutrition as $10 \mu \mathrm{L}$ and $50 \mu \mathrm{L}$. The incubation was performed during $24-48$ hours at $37^{\circ} \mathrm{C}$. The results were evaluated as CFU (Colony Forming Unit) per gram, quantitatively.

\section{Statistical analyses}

The average and standard deviation values of all groups were compared statistically with each other by using SPSS (Statistical Package for the Social Sciences) programme for windows 10.0. Statistical evaluation was also made by using Kruskal-Wallis variance analyses. The results were reported to be statistically meaningful if $p$ value was less than 0.05 .

\section{Results}

The results of total bilirubin, direct bilirubin, AST, ALT, ALP and GGT from blood samples of the rats were shown in Figure 1 and Table 1.

It was observed that Group $C$ had the highest values of total bilirubin (15.95 \pm 3.79$)$ and direct bilirubin (11.37 \pm 2.54$)$. Also, it was observed that Group B had the highest values of AST (1558.71 \pm 837.2$)$, ALT (513.0 \pm 255.30$)$, GGT (67.85 \pm 35.80$)$ and ALP (727.0 \pm 651.23$)$.

The average values of CFU and standard deviation were shown in Table 2 and Figures 2, 3. When all the groups were compared with each other for the samples of $10 \mu \mathrm{L}$ and $50 \mu \mathrm{L}$, bacterial growth was observed in the mesenteric lymph nodes in all groups. While the highest bacterial growth in mesenteric lymph nodes was observed in Group D for the samples of $10 \mu \mathrm{L}$, for $50 \mu \mathrm{L}$ this was observed in Group C (Table 2). 
Table 1. The average and standard deviation values of biochemical parameters

\begin{tabular}{|lccccccc|}
\hline & $\begin{array}{c}\text { Total bilirubine } \\
(\mathrm{mg} / \mathrm{dL})\end{array}$ & $\begin{array}{c}\text { Direct bilirubine } \\
(\mathrm{mg} / \mathrm{dL})\end{array}$ & $\begin{array}{c}\text { Indirect bilirubine } \\
(\mathrm{mg} / \mathrm{dL})\end{array}$ & $\begin{array}{c}\text { AST } \\
(\mathrm{U} / \mathrm{L})\end{array}$ & $\begin{array}{c}\text { ALT } \\
(\mathrm{U} / \mathrm{L})\end{array}$ & $\begin{array}{c}\text { GGT } \\
(\mathrm{U} / \mathrm{L})\end{array}$ & $\begin{array}{c}\text { ALP } \\
(\mathrm{U} / \mathrm{L})\end{array}$ \\
\hline $\mathrm{A}$ & $2.88 \pm 2.10$ & $0.12 \pm 0.10$ & $2.71 \pm 2.04$ & $284.28 \pm 199.10$ & $114.85 \pm 77.54$ & $3.57 \pm 1.81$ & $217.28 \pm 69.86$ \\
B & $10.14 \pm 1.72$ & $7.69 \pm 1.35$ & $2.45 \pm 1.14$ & $1558.71 \pm 837.22$ & $513.00 \pm 255.30$ & $67.85 \pm 35.80$ & $727.00 \pm 651.23$ \\
C & $15.95 \pm 3.79$ & $11.37 \pm 2.54$ & $4.57 \pm 2.04$ & $763.14 \pm 846.81$ & $181.85 \pm 135.55$ & $50.57 \pm 21.21$ & $599.14 \pm 110.58$ \\
D & $12.04 \pm 2.40$ & $9.19 \pm 2.08$ & $2.84 \pm 0.41$ & $755.71 \pm 295.94$ & $202.00 \pm 64.84$ & $51.85 \pm 6.03$ & $598.28 \pm 207.27$ \\
\hline \multicolumn{7}{|l}{ (A: Sham group, B: Control group, C: High-fat enteral nutrition group, D: Low-fat enteral nutrition group) } \\
\end{tabular}

Table 2. The average values of CFU and standard deviation for $10 \mu \mathrm{L}$ and $50 \mu \mathrm{L}$ of growth in groups

\begin{tabular}{|ccccccc|}
\hline Group & $\boldsymbol{\mu L}$ & Lung & Liver & MLN & Spleen & Blood \\
\hline 10 & - & - & $7.94 \pm 15.73$ & $4.91 \pm 12.99$ & - \\
& 50 & - & - & $1.82 \pm 3.22$ & $0.98 \pm 2.59$ & - \\
10 & - & - & $8.68 \pm 9.31$ & - & - \\
50 & - & $0.58 \pm 1.54$ & $7.65 \pm 20.24$ & - & - \\
10 & - & $0.11 \pm 0.30$ & $25.64 \pm 67.43$ & - & - \\
& $0.06 \pm 0.11$ & $17.08 \pm 45.18$ & $10.21 \pm 13.72$ & - \\
\hline
\end{tabular}

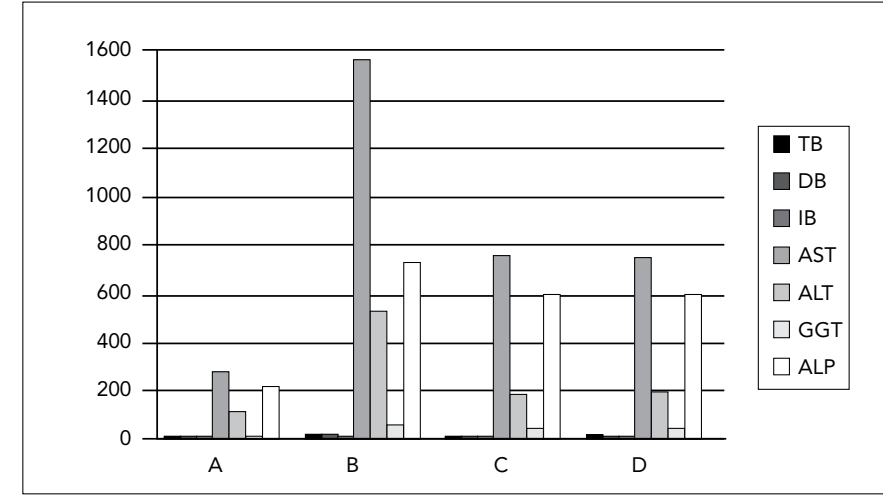

Figure 1. The comparison of average values of biochemical results

(TB: Total Bilirubine, DB: Direct Bilirubine, IB: Indirect Bilirubine, AST: Aspartate Aminotransferase, ALT: Alanine Aminotransferase, GGT: Gamma-glutamyl Transferase, ALP: Alcaline Phosphatase)

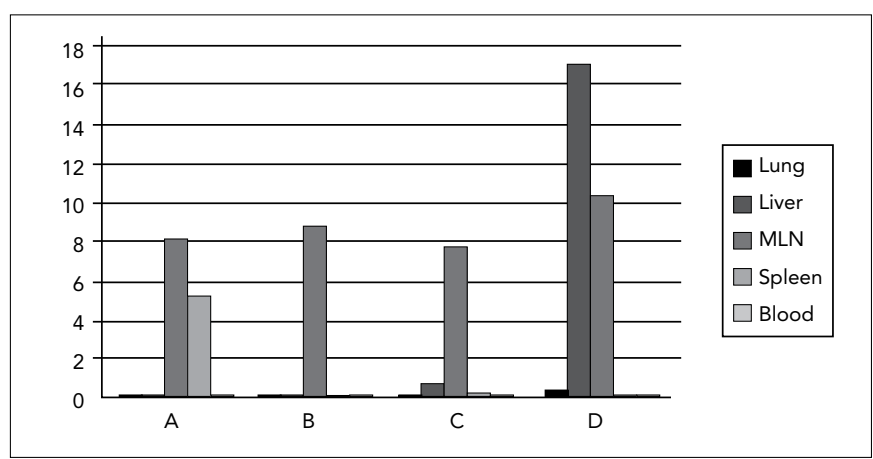

Figure 2. The comparison of average CFU values for $10 \mu \mathrm{L}$ of growth in groups

(MLN: Mesenteric Lymph Nodes)

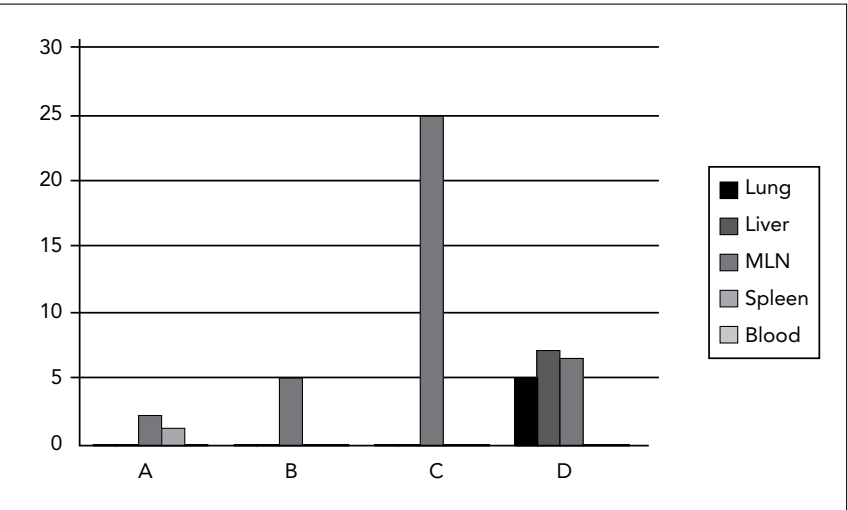

Figure 3. The comparison of average CFU values for $50 \mu \mathrm{L}$ of growth in groups

(MLN: Mesenteric Lymph Nodes)

Table 3. Statistical results for $10 \mu \mathrm{L}$ and $50 \mu \mathrm{L}$ of growth in groups

\begin{tabular}{|lccccc|}
\hline & Lung & Liver & MLN & Spleen & Blood \\
\hline $10 \mu \mathrm{L}$ & 0.392 & 0.556 & 0.256 & 0.392 & 1.000 \\
$50 \mu \mathrm{L}$ & 0.211 & 0.556 & 0.103 & 0.392 & 1.000 \\
\hline
\end{tabular}

The $\mathrm{p}$ results from Kruskal-Wallis variance analysis were shown in Table 3. As the values were higher from 0.05, the differences among the groups were not found statistically meaningful.

\section{Discussion}

Despite the improvements in antibacterial treatments, sepsis is declared as the major reason for mortality in the 
patients who have trauma or major surgical procedures. The reduced neutrophil chemotaxis and bactericidal activity after trauma, and the reduction in colony stimulating factors facilitate the sepsis (23).

Wells et al. (24) reported that the translocation of intestinal bacteria to other organs is achieved by the macrophages. The macrophages increase on the gut wall, and phagocytise the microorganisms, however these live microorganisms in the macrophages are set free due to the death of macrophages carried to other organs, which leads to BT (24).

It was reported by many studies that BT is provided by the lymphatic system $(25,26)$. Reporting no growth in the blood samples from operated rats, but the first and greatest growth in mesenteric lymph nodes, the present study similarly supports the view that lymphatic system is essential way for BT.

If bacteria which are translocated to mesenteric lymph nodes have high virulence or the organism has an inadequate immune system, bacteria can be spread to distant organs like the liver and spleen. Finally, bacteria pass to thesystemic circulation $(27,28)$.

The advantage of early oral nutrition is that intestinal blood circulation increases, which decreases the hypovolemia and ischemia in the gut, having an important role in translocation (29).

Although the BT in bile duct ligated models was investigated before (15-22), in many of them $(15-17,19-22)$ the effects of different materials on BT, except food with high-fa was studiedt. In previous studies, the effects of high-fat enteral nutrition on BT were studied by Luyer et al. $(10,11,18)$. Although in all of these studies the hemorrhagic shock were used for the models, in only one of them was obstructive jaundice formed. In our study, the bile duct ligated models without hemorrhagic shock were used to feed on high-fat nutrition. Luyer et al. (18) have investigated the levels of plasma endotoxin and tumor necrosis factor-alpha (TNF- $\alpha$ ) after a hemorrhagic shock procedure in bile duct ligated rats fed on high-fat nutrition during seven days. It has also been observed that the levels of plasma endotoxin greatly decreased after hemorrhagic shock in the bile duct ligated rats fed on high-fat nutrition. Interestingly, it has been observed that the decrease in the levels of plasma endotoxin is related to intraluminal bile salts and it is not directly affected by triacylglycerol malabsorption (18). It was also observed that the levels of TNF- $\alpha$ decreased significantly in the rats fed on high-fat nutrition when compared with rats fed on low-fat nutrition (18). In our study, only BT was investigated in the bile duct ligated models that were fed on high-fat nutrition and without using hemorrhagic shock.

When our study was compared with previous studies performed on the models without using hemorrhagic shock, some results were evaluated. Erbil et al. (16) have studied the effects of deoxycholate, lactulose and glutamine, and they have reported that all products cause a decrease in BT, however, glutamine has the most decreasing power. Aldemir et al. (17) have researched the effects of ursodeoxycholic acid, glutamine and polyclonal immunoglobulin, and they have found that all of the products decrease BT. Geyik et al. (21) have studied the effects of an yeast and they recorded that the Saccharomyces boulardii decreases BT in the models with obstructive jaundice. Likewise, the findings of Gencay et al. (22). They have reported that honey decreases the BT (22). It was also reported by Kaya et al. (20) that ciprofloxacin and ursodeoxycholic acid decrease BT. Furthermore, Karatepe et al. (19) have recorded that glutamine and curcumin decrease BT in the rat models with obstructive jaundice.

In our study, the bacterial growth was observed in mesenteric lymph nodes in all groups. For the samples of 10 $\mu \mathrm{L}$, the highest bacterial growth occurred in lung, liver and mesenteric lymph nodes of bile duct ligated rats fed on the products of low-fat nutrition. When the bacterial growth in mesenteric lymph nodes for $10 \mu \mathrm{L}$ samples was compared, much closer values were observed in Group C (high-fat enteral nutriton group) and Group A (control group) (Table 2). The bacterial growth in mesenteric lymph nodes for $10 \mu \mathrm{L}$ samples in Group D (low-fat enteral nutrition) was observed to be more than Group B (standard nutrition) and the others, respectively. So, our study has indicated that the bacterial growing in mesenteric lymph nodes for $10 \mu \mathrm{L}$ samples of rats in the high-fat enteral nutrition group were found to be lower than the rats in both sham and low-fat enteral nutrition groups. Therefore, it may be mentioned that high-fat enteral nutrition may cause a decreae of bacterial growth in mesenteric lymph nodes. However, when the results on bacterial growth in all samples (blood and the other tissues) were evaluated in total, it is very difficult to say that high-fat enteral nutrition decreases the BT. because the bacteria growing in the other samples were not found meaningful. For example, the highest bacterial growth in mesenteric lymph nodes for $50 \mu \mathrm{L}$ samples was observed in the high-fat enteral nutrition group. When all findings from the tissues were evaluated, the results were not found to be meaningful. The statistical evaluation supported the results.

\section{Conclusion}

Bacterial Translocation is a very important problem following surgical operations. Although it was observed in this experimental study that high-fat enteral nutrition has no meaningful effect on decreasing BT in bile duct ligated rats, it is need a lot of different experimental and clinical studies to explain the relationships between enteral nutrition and BT.

\section{Acknowledgements}

We would like to thank to Departments of Clinical Microbiology and Biochemistry of Faculty of Medicine at Kocaeli University for their kindly helps. Also, we thank to Prof. Dr. Aynur Karadenizli (Department of Clinical Microbiology, Faculty of Medicine, Kocaeli University) for microbiological guidance, to Assoc. Prof. Dr. Mustafa Çekmen (Department of Biochemistry, Faculty of Medicine, Kocaeli University) for biochemical guidance and to Prof. Dr. N. Zafer Cantürk (Department of General Surgery, Faculty of Medicine, Kocaeli University) to statistical guidance. 


\section{Conflict of Interest}

No conflict of interest was declared by the authors.

\section{References}

1. Kimmings AN, Van Deventer SJH, Obertop H, Rauws EAJ, Huibregtse K, Gouma DJ. Endotoxin, cytokines, and endotoxin binding proteins in obstructive jaundice and after preoperative biliary drainage. Gut 2000;46:725-31. [CrossRef]

2. Clements WDB, Erwin P, McCaigue MD, Halliday MI, Barclay GR, Rowlands BJ. Conclusive evidence of endotoxemia in biliary obstruction. Gut 1998;42:293-9. [CrossRef]

3. Kordzaya DJ, Goderdzishvili VT. Bacterial translocation in obstructive jaundice in rats: role of mucosal lacteals. Eur J Surg 2000;166:367-74. [CrossRef]

4. Kimmings AN, Van Deventer SJH, Obertop H, Gouma DJ. Treatment with recombinant bactericidal/permeability-increasing protein to prevent endotoxin-induced mortality in bile duct-ligated rats. J Am Coll Surg 1999;189:374-9. [CrossRef]

5. Comert M, Taneri F, Tekin E, Ersoy E, Oktemer S, Onuk E, et al. The effect of pentoxifylline on the healing of intestinal anastomosis in rats with experimental obstructive jaundice. Surg Today 2000;30:896-902. [CrossRef]

6. Reynold JV, Murchan P, Leonard N, Clarke P, Keane FBV, Tanner WA. Gut barier failure in experimental obstructive jaundice. J Surg Res 1996;62:11-6. [CrossRef]

7. Memiş D, Yelken B, Şahin SH, Vatan I, Yardım T. The effect of the prebiotic solutions in treatment of severe sepsis. Balkan Med J 2007;24:194-9.

8. Nieuwenhuijs VB, Van Dijk JE, Gooszen HG, Akkermans LMA. Obstructive jaundice, bacterial translocation and interdigestive smallbowel motility in rats. Digestion 2000;62:255-61. [CrossRef]

9. Gencer A, Ozdemir Y, Sucullu I, Filiz Al, Yucel E, Akin ML, et al. The effects of enteral immunonutrient products and total parenteral nutrition in patients who underwent major abdominal surgery. Balkan Med J 2010;27:404-10.

10. Luyer MD, Jacobs J, Vreugdenhil AC, Hadfoune $M$, Dejong $C H$, Buurman WA, et al. Enteral administration of high-fat nutrition before and directly after hemorrhagic shock reduces endotoxemia and bacterial translocation. Ann Surg 2004;239:257-64. [CrossRef]

11. Luyer MD, Buurman WA, Hadfoune M, Jacobs JA, Konstantinov $\mathrm{SR}$, Dejong $\mathrm{CH}$, et al. Pretreatment with high-fat enteral nutrition reduces endotoxin and tumor necrosis factor-alpha and preserves gut barrier function early after hemorrhagic shock. Shock 2004;21:65-71. [CrossRef]

12. Vreugdenhil AC, Rousseau CH, Hartung $T$, Greve JW, van't Veer C, Buurman WA. Lipopolysaccharide (LPS)-binding protein mediates LPS detoxification by chylomicrons. J Immunol 2003;170:1399-405

13. Parks RW, Clements WD, Smye MG, Pope C, Rowlands BJ, Diamond T. Intestinal barrier dysfunction in clinical and experimental obstructive jaundice and its reversal by internal biliary drainage. Br J Surg 1996;83:1345-9. [CrossRef]

14. Sewnath ME, Karsten TM, Prins $M H$, Rauws EJ, Obertop $H$, Gouma DJ. A meta-analysis on the efficacy of preoperative bili- ary drainage for tumors causing obstructive jaundice. Ann Surg 2002;236:17-27. [CrossRef]

15. Parks RW, Stuart Cameron CH, Gannon CD, Pope C, Diamond T, Rowlands BJ. Changes in gastrointestinal morphology associated with obstructive jaundice. J Path 2000;192:526-32. [CrossRef]

16. Erbil $Y$, Berber E, Ozarmagan S, Seven R, Eminoglu L, Calis A, et al. The effects of sodium deoxycholate, lactulose and glutamine on bacterial translocation in common bile duct ligated rats. Hepatogastroent 1999;46:2791-8.

17. Aldemir M, Geyik MF, Kokoglu OF, Buyukbayram H, Hosoglu S, Yagmur Y. Effects of ursodeoxycholic acid, glutamine and polyclonal immunoglobulins on bacterial translocation in common bile duct ligated rats. ANZ J Surg 2003;73:722-6. [CrossRef]

18. Luyer MDP, Buurman WA, Hadfoune M, Jacobs JA, Dejong CHC, Greve JVM. High-fat enteral nutrition reduces endotoxin, tumor necrosis factor-alpha and gut permeability in bile duct-ligated rats subjected to hemorrhagic shock. J Hepatol 2004;41:377-83. [CrossRef]

19. Karatepe O, Acet E, Battal M, Adas G, Kemik A, Altiok M, et al. Effects of glutamine and curcumin on bacterial translocation in jaundiced rats. World J Gastroenterol 2010;16:4313-20. [CrossRef]

20. Kaya O, Ozdemir F, Atli M, Aslan V, Cagatay M, Anlar M, et al. The effects of ciprofloxacin and ursodeoxycholic acid on bacterial translocation in obstructive jaundice. Turk J Gastroenterol 2009;20:186-91.

21. Geyik MF, Aldemir M, Hosoglu S, Ayaz C, Satilmis S, Buyukbayram $\mathrm{H}$, et al. The effects of Saccharomyces boulardii on bacterial translocation in rats with obstructive jaundice. Ann R Coll Surg Engl 2006;88:176-80. [CrossRef]

22. Gencay C, Kilicoglu SS, Kismet K, Kilicoglu B, Erel S, Muratoglu $S$, et al. Effect of honey on bacterial translocation and intestinal morphology in obstructive jaundice. World J Gastroenterol 2008;14:3410-5. [CrossRef]

23. Gennari R, Alexander W, Gianotti L, Eaves-Pyles T, Hartmann S. Granulocyte macrophage colony stimulating factor improves survival in two models of gut derived sepsis by improving gut barrier function and modulating bacterial clearance. Ann Surg 1994;220:68-76. [CrossRef]

24. Wells $C L$, Maddaus MA, Simmons RL. Role of the macrophage in the translocation intestinal bacteria. Arch Surg 1987;122:48-53. [CrossRef]

25. Narioka J, Nishi M, Ogata Y, Kuwahara T, Nakayama H, Tashiro $\mathrm{S}$, et al. Promotion of bacterial translocation by major liver resection in obstructive jaundice in rats colonised predominantly with indigenous Escherichia coli. J Med Microbiol 2002;51:687-94.

26. Wang XD, Parsson H, Andersson R, Soltesz V, Johansson K, Bengmark S. Bacterial translocation, intestinal ultrastructure and cell membrane permeability early after major liver resection in the rat. Br J Surg 1994;81:579-84. [CrossRef]

27. Wiest R, Rath HC. Gastrointestinal disorders of the critically ill. Bacterial translocation in the gut. Best Pract Res Clin Gastroenterol 2003;17:397-425. [CrossRef]

28. Berg RD. Bacterial translocation from the gastrointestinal tract. Trends Microbiol 1995;3:149-54. [CrossRef]

29. Gianotti R, Alexander W, Nelson JL, Fukushima R, Pyles T, Chalk $\mathrm{CL}$. Role of early enteral feeding and acute starvation on postburn bacterial translocation and host defense: prospective, randomized trials. Critical Care Med 1994;22:265-72. [CrossRef] 